\title{
The relationship between degeneration and asymmetry of the lumbar multifidus and erector spinae muscles in patients with lumbar disc herniation with and without root compression
}

Alikemal Yazici ( $\sim$ alikemalyazici@hotmail.com)

Near East University

Tuba Yerlikaya

Near East University

\section{Research Article}

Keywords: lumbar disc herniation, root compression, muscle degeneration, asymmetry, magnetic resonance imaging

Posted Date: May 19th, 2022

DOI: https://doi.org/10.21203/rs.3.rs-1357587/v2

License: (c) (i) This work is licensed under a Creative Commons Attribution 4.0 International License. Read Full License 


\section{Abstract}

Background: Determination of muscle pathologies in lumbar disc herniation (LDH) and other cases with low back pain is important for the understanding of low back problems and the determination of appropriate treatment methods. The aim of the current study was to compare degeneration and asymmetry of the lumbar musculus multifidus (MF) and lumbar musculus erector spinae (ES) muscles with magnetic resonance imaging (MRI) in patients with lumbar discopathy with and without radiculopathy and to predict the importance of removal of root compression in patients with radiculopathy by revealing whether root compression has an effect on the severity of muscle degeneration.

Methods: The patients were examined in 2 groups as 56 patients with lumbar discopathy and no radiculopathy (Non-rad group) and 51 patients with lumbar discopathy and radiculopathy (Rad group). On axial MRI slices passing the centre of the disc at L3-S1 level, the asymmetry, CSA, fat infiltration, and total CSA (TCSA=MF+ES) of the MF and ES muscles were measured and compared.

Results: No difference was seen between the groups in respect of the CSA values of the right and left MF and left ES, and a significant difference was determined in the right ES CSA $(p=0.021)$. The CSA and TCSA of the MF and ES showed no asymmetry according to the groups. Severe fat infiltration of $>50 \%$ was determined in the Rad group at a higher rate than in the Non-rad group in the right and left MF and left ES. Fat infiltration was determined to be significantly correlated with age, body mass index, and duration of pain $(p<0.001, p<0.001, p=0.004)$.

Conclusions: The study results showed a correlation between LDH and paraspinal muscle degeneration, while no correlation was determined with asymmetry. It can be considered that severe $(>50 \%)$ fat infiltration is associated with nerve root compression, originating from the development of more severe degeneration because of the denervation associated with the compression. Therefore, it can be recommended that immediate correction of nerve root compression with appropriate medical treatment methods to stop and correct denervation is applied, and in non-responsive cases, surgical elimination of the pressure.

\section{Background}

Lumbar disc herniation (LDH) is one of the causes of low back pain. Asymptomatic LDH is seen at the rate of 0.5-20\%, and symptomatic LDH at 1-3\%. The male/female ratio of LDH is 2/1 and it is most often seen between 30 and 50 years of age. In 95\% of cases, LDH is at the level of L4-5 or L5-S1 [1-4]. LDH is defined as localised or widespread movement of disc material (nucleus pulposus or annulus fibrosis) to outside the intervertebral disc space [1, 5]. LDH causes narrowing of the spinal canal and neural foramen leading to pain, muscle spasm, restricted movement, and nerve compression of varying degrees, which may then cause several symptoms to be seen even as far as sensory and motor neurological deficits [6, 7]. In clinical practice, it is generally overlooked that LDH affects the paraspinal muscles $[7,8]$.

The paraspinal muscles are responsible for the control of intersegmentary movements with movements of the spine and extremities, and they have unique architecture and design features $[9,10]$. From the paraspinal muscle group, the MF and ES muscles are the two main muscle groups functioning in lumbar stabilisation [9].

The paraspinal muscles are of critical importance for spinal health. Parspinal muscle dysfunction and failure is common in patients with low back pain [11]. LDH and other causes of low back pain, and many spine pathologies cause changes in the paraspinal muscles. These changes include an increase in fat and connective tissue in the muscle, fibre type changes, distorted cell populations, altered gene epression, low muscle resistance, low muscle strength, and muscle atrophy [12-19]. These findings are seen in parallel with denervation and re-innervation of the parspinal muscles in disc herniation and nerve root compression $[11,20]$.

Many studies have been conducted to reveal the status of the paraspinal muscles in patients with LDH and other low back pain. Changes in muscle tissue composition such as fat-fibrotic infiltration, muscle atrophy, and changes in fibre types have been shown to be different on the point of asymmetry in patient populations and animal studies compared with control groups. Some of these studies have been clinical observational studies [19, 21-28], some have been histological studies [12, 29], and some have examined stem cell and gene analyses $[15,16,30]$. There are also publications in literature of experimental animal model studies [17, 20,31-34], and studies that have examined the changes occurring naturally in animals [35, 36].

Previous studies have reported that a higher rate of fat-fibrotic infiltration is observed in the paraspinal muscles in patients with LDH, type I fibers (slow twitch and fatigue resistant fibers) decrease, and type IIX fibers (fast twitch fibers less resistant to fatigue) increase. In addition, it has been shown that paraspinal muscles contain more stem cells in patients with LDH and these stem cells have more fibrogenic and adipogenic gene expression (12,26,37).

Studies examining degeneration and dysfunction of the paraspinal muscles could be of guidance in preventing the formation of spine pathologies or in treatment planning. Therefore, the primary aim of this study was to compare the relationships between the CSA and fat infiltration of the MF and ES muscles in patients with LDH-related low back pain with and without nerve root compression, to reveal whether root compression has an effect on the severity of muscle degeneration. The second objective was to reveal the relationship between the asymmetry and degeneration of the muscles and the severity of the nerve compression (radiculopathy) and to determine the relationship between all the data and the sociodemographic- physical characteristics, segmentation, and herniation.

\section{Methods}

\section{Participants}


This observational cross-sectional study included 107 patients who presented at the Orthopaedics and Traumatology Clinic between February and May 2021 with complaints of low back pain and were diagnosed with LDH with magnetic resonance imaging (MRI). The patients were aged 20-65 years, and described low back pain ongoing for the last 3 months. Two groups were formed of patients with low back pain with radiculopathy (Rad group) and without radiculopathy (Non-rad group). All the study participants provided signed informed consent forms. Approval for the study was granted by the Local Ethics Committee (decision no: YDU/2021/87-1273).

The Non-rad group included 56 patients determined with LDH only on MRI, with no findings of nerve root compression in the neuromuscular examination, no radicular pain, and negativity in specific lumbar tests (straight leg raise, contraleteral straight leg raise, Laseque test, femoral nerve tension test). When nerve compression was suspected, EMG was requested. Patients with nerve compression determined on MRI and EMG, and those with degenerative disc disorders were not included in the Non-rad group. The Rad group included 51 patients with radicular pain in the leg, positivity in the specific lumbar tests, and findings of nerve root compression on EMG and MRI.

MRIs were taken of patients to reveal the etiology of the low back pain. The hernia types were classified as median, paramedian, foraminal, or extraforaminal according to the localisation of the protruding section of the disc and as bulging, protrusion, extrusion, or sequestration, based on the degree of protrusion on MRI [38,39]. The MRI-based nerve compression grading system was used to classify radiculopathy in this study [40, 41].

Low back pain was accepted as pain between the inferior edge of the costae and the gluteal fold. Radicular pain was accepted as pain from below the gluteal fold striking the thigh, leg and foot. The pain was described by the patient and confirmed by the physician performing the examination. Pain intensity was evaluated using a standard $100 \mathrm{~mm}$ visual analog scale (VAS).

Patients were excluded from the study if they had deformities, malformations, pelvic disorders, rheumatological diseases, or infections affecting the spine, or if they had a history of lumbar surgery. The demographic, clinical, and disease-related data were obtained from the patients in face-to-face interviews. In patients where a differential diagnosis was necessary, C-reactive protein (CRP), antistreptolysin O (ASO), rheumatoid factor (RF), hemogram, erythrocyte sedimentation rate (ESR), full urine analysis, salmonella and brucella tests were requested. The examinations of the 107 patients were made by 2 physicians with 25 years of experience in spinal surgery and the lumbar spine MR images were analyzed by an experienced consultant and radiology specialist blinded to the clinical history. The MR images were all taken by the same radiology technician.

\section{Measurements}

\section{Magnetic Resonance Imaging}

Imaging was performed with a 1.5 Tesla MR device (Signa Explorer SV25.3 16 channel, up-to-date software, General Electric, Milwaukee, WI, USA). Shots were taken with the patient positioned supine, with a routine protocol for the lumbar spine with the measurement level between L3-S1 (L3-4 / L4-5 / L5-S1) at the center of the disc. Turbo spin-echo T1 and T2-weighted sagittal, and turbo spin-echo T2 axial 4mm sections parallel to the disc spaces were taken. Evaluations were made on T2 axial sections. The asymmetry, fat content, CSA, and TCSA were examined of the right and left sides of the MF and ES (m.iliocostalis and m.longissimus) at the L3-S1 level. The technical values were TR 400-600, TE 15-25, thickness 4 mm, band width 25-150, rotational angle $90^{\circ}$ for T1, and TR 3000-4000, TE 100-120, thickness $4 \mathrm{~mm}$, band width $25-150$, rotational angle $130^{\circ}-150^{\circ}$ for T2 images, and the acquisition time was mean 10 mins.

Assured reliability has been found in the evaluation of muscle-related changes on MRI [42, 43]. It has been stated that MRI has higher image resolution and provides better determination of muscle and soft tissues such as fat compared to ultrasound and computed tomography scans [44-46]. Muscle degeneration is usually evaluated on axial MRIs on T1 and T2-weighted sequences (Figure 1) [43, 44, 46]. It has been reported that muscle degeneration can be observed on MRI as a decrease in muscle size or an increase in fat accumulation $[13,18]$.

In this study, fat infiltration was evaluated semi-quantitatively. The CSA was measured by determining the fascial borders (epimysium) of the muscles and using PACS Report (picture archive and communication system) and manual drawing. In the evaluation, fat infiltration was defined as replacement of the muscle mass with fat and fibrous tissue of $<10 \%$ as normal, $10 \%-50 \%$ as moderate and $>50 \%$ as severe (Figure 2 ) [19, 22]. Asymmetry was calculated as "the largest edge - the smallest edge/ the largest edge $x 100$ " and stated as a percentage (\%) [47].

For internal reliability, 15 randomly selected patients were re-evaluated by the same radiologist after an interval of one month. The intra-observer kappa agreement value obtained was 0.953 .

\section{Statistical Analysis}

Data obtained in the study were analyzed statistically using IBM SPSS vn. 23 software (IBM, Chicago, IL, USA). Taking the CSA mean values into consideration, it was determined to be necessary to have a minimum sample size of 110 subjects with 55 in each group for $95 \%$ confidence (1-a), $95 \%$ test power $(1-\beta)$ and effect size of $f=0.634$. The study was completed with a total of 107 subjects, as 56 in the Non-rad group and 51 in the Rad group. According to the post hoc power analysis, the test power with 107 subjects was determined as $94.7 \%$ [48].

The MANOVA test was used in the comparisons of CSA and TCSA values according to group, segment, and gender. In multiple comparisons, the Duncan test was used. In the comparisons of age, BMI, duration of low back pain and VAS values between the Rad and Non-rad groups, the Mann Whitney U-test was used. The Chi-square test was applied in the comparisons of categorical data. A value of $p<0.05$ was accepted as statistically significant. 


\section{Results}

The demographic characteristics of the patients are shown in Table 1. No significant differences were seen between the groups in respect of the mean values of age, gender, BMI, and the duration of low back pain. Statistically significant differences were determined between the groups in respect of pain severity as resting and activity VAS values $(p<0.001)$.

Table 1 Comparisons of the demographic characteristics of the groups

\begin{tabular}{llllllll} 
& Non-rad & & Rad & & Total & P \\
& $\pm \sigma$ & Median (min-max) & $\pm \sigma$ & Median (min-max) & $\pm \sigma$ & Median (min-max) \\
\hline Age (years) & $49.3 \pm 9.2$ & $49.5(27-65)$ & $49.5 \pm 10.6$ & $48(23-65)$ & $49.4 \pm 9.8$ & $49(23-65)$ & $0.931^{1}$ \\
\hline BMI (m $\left.{ }^{2} / \mathrm{kg}\right)$ & $29.3 \pm 5$ & $28.6(20-43)$ & $29.9 \pm 5.3$ & $29.8(18-47)$ & $29.6 \pm 5.1$ & $29.7(18-47)$ & $0.595^{1}$ \\
\hline LBP duration(months) & $55.5 \pm 55$ & $36(3-240)$ & $53.2 \pm 64.3$ & $24(3-300)$ & $54.4 \pm 59.3$ & $36(3-300)$ & $0.604^{2}$ \\
\hline VAS resting & $2.6 \pm 1.5$ & $2(1-7)$ & $5.9 \pm 2.9$ & $7(1-10)$ & $4.2 \pm 2.8$ & $3(1-10)$ & $<(2-10)$ \\
\hline VAS activity & $4.7 \pm 1.9$ & $4.5(2-9)$ & $7.8 \pm 2.4$ & $8(2-10)$ & $6.2 \pm 2.6$ & $<.001^{2}$ \\
\hline Gender & $\mathrm{n}(\%)$ & & $\mathrm{n}(\%)$ & & & $<0.001^{2}$ \\
\hline Male & $13(23.2)$ & & $17(33.3)$ & & $30(28.0)$ &
\end{tabular}

${ }^{1}$ Independent Samples t-test, ${ }^{2}$ Mann Whitney U-test, ${ }^{3}$ Pearson Chi Square test, LBP: Low Back Pain

The comparisons of the CSA and TCSA values of the groups according to gender and segment are shown in Table 2. No difference was seen in the CSA of the right and left MF and the left ES between the groups, and a significant difference was determined in the right $E S(p=0.021)$. The mean value of the Nonrad group was lower. The mean right TCSA values showed a significant difference with lower values obtained in the Non-rad group ( $p=0.005)$.

Table 2 Comparisons of the CSA and TCSA values of the groups according to gender and segment

\begin{tabular}{|c|c|c|c|c|c|c|c|c|c|c|c|c|c|c|}
\hline & \multirow{2}{*}{$\begin{array}{l}\text { Group } \\
\text { P }\end{array}$} & & \multicolumn{2}{|c|}{ Gender } & \multicolumn{2}{|c|}{ Segment } & \multicolumn{2}{|c|}{ Group^Gender } & \multicolumn{2}{|c|}{ Gender*Segment } & \multicolumn{2}{|c|}{ Group*Segment } & \multicolumn{2}{|c|}{ Group*Gender*Segmen } \\
\hline & & & $\mathrm{p}$ & & $\mathrm{p}$ & & $\mathrm{P}$ & & $\mathrm{p}$ & & $\mathrm{p}$ & & $\mathrm{P}$ & \\
\hline $\begin{array}{l}\text { Right MF } \\
\left(\mathrm{CSA}, \mathrm{mm}^{2}\right. \\
)^{2}\end{array}$ & 0.075 & 0.010 & 0.000 & 0.051 & 0.000 & 0.533 & 0.319 & 0.003 & 0.998 & 0.000 & 0.857 & 0.001 & 0.609 & 0.003 \\
\hline $\begin{array}{l}\text { Left MF } \\
\left(\mathrm{CSA}, \mathrm{mm}^{2}\right)\end{array}$ & 0.579 & 0.001 & 0.640 & 0.001 & 0.000 & 0.103 & 0.718 & 0.000 & 0.618 & 0.003 & 0.731 & 0.002 & 0.759 & 0.002 \\
\hline $\begin{array}{l}\text { Right ES } \\
\left(\mathrm{CSA}, \mathrm{mm}^{2}\right)\end{array}$ & 0.021 & 0.017 & 0.000 & 0.100 & 0.000 & 0.286 & 0.245 & 0.004 & 0.111 & 0.014 & 0.005 & 0.034 & 0.980 & 0.000 \\
\hline $\begin{array}{l}\text { Left ES } \\
\left(\mathrm{CSA}, \mathrm{mm}^{2}\right)\end{array}$ & 0.059 & 0.012 & 0.000 & 0.063 & 0.000 & 0.261 & 0.022 & 0.017 & 0.307 & 0.008 & 0.043 & 0.020 & 0.879 & 0.001 \\
\hline $\begin{array}{l}\text { Right } \\
\text { TCSA } \\
\text { (Right } \\
\text { MF+Right } \\
\text { ES mm²) }\end{array}$ & 0.005 & 0.025 & 0.000 & 0.133 & 0.000 & 0.051 & 0.152 & 0.007 & 0.159 & 0.012 & 0.013 & 0.028 & 0.979 & 0.000 \\
\hline Left TCSA & 0.518 & 0.001 & 0.003 & 0.029 & 0.193 & 0.011 & 0.298 & 0.004 & 0.247 & 0.009 & 0.691 & 0.002 & 0.781 & 0.002 \\
\hline $\begin{array}{l}\text { (Left } \\
\text { MF+Left } \\
\text { ES mm²) }\end{array}$ & & & & & & & & & & & & & & \\
\hline
\end{tabular}

: Partial Eta squared, Age and BMI were added to the model as covariate variables. MF: Lumbar musculus multifidus, ES: Lumbar musculus erector spinae

The right MF, right and left ES mean CSA values, and right and left mean TCSA values showed a difference according to gender, with higher values obtained in males than in females $(p<0.001, p<0.001, p<0.001, p<0.001$, and $p=0.003$, respectively).

According to segments, the highest mean values of right and left MF CSA were in the L5-S1 segment, and the lowest mean values were in the L3-L4 segment $(p<0.001)$. The highest mean values of right and left ES CSA were in the L3-L4 segment, and the lowest mean values were in the L5-S1 segment $(p<0.001)$. The mean TCSA values also showed a significant difference according to segments $(p<0.001)$. 
No difference was determined between the mean values according to the relationship with gender and segment. The mean right and left ES CSA values in the L5-S1 segment according to group and segment were determined to be lower in the Rad group than in the Non-rad group ( $p=0.005, p=0.043$ ).

The results of the correlation analyses between the CSA values of the groups and age, BMI, pain duration, and pain severity (resting and activity VAS) scores are shown in Table 3. In the Non-rad group, a weak positive correlation was determined between age and the left ES CSA and left TCSA ( $r=0.270$, $r=0.271$, respectively). In the Rad group, a weak negative correlation was determined between age and the right MF CSA ( $r=-0.281)$. In the Non-rad group, a moderate-level positive correlation was determined between BMI and the right and left ES CSA and TCSA $(r=0.520, r=0.482, r=0.462, r=0.422$, respectively). No relationship was determined between the duration and severity of pain and CSA and TCSA.

Table 3 Results of the correlation analyses between the CSA values of the groups and clinical features

\begin{tabular}{|c|c|c|c|c|c|c|}
\hline Group & & Age & BMI & Duration of LBP & VAS Resting & VAS Activity \\
\hline \multirow[t]{6}{*}{ Non-rad } & Right MF.(CSA,mm²) & 0.104 & 0.023 & -0.031 & -0.219 & -0.055 \\
\hline & Left MF.(CSA,mm²) & 0.089 & -0.024 & -0.093 & -0.181 & -0.002 \\
\hline & Right ES.(CSA,mm²) & 0.174 & $0.520^{*}$ & -0.059 & -0.119 & -0.022 \\
\hline & Left ES.(CSA,mm²) & $0.270^{*}$ & $0.482^{*}$ & -0.093 & -0.052 & 0.062 \\
\hline & Right TCSA.(Right MF+Right ES mm²) & 0.184 & $0.462^{*}$ & -0.061 & -0.170 & -0.036 \\
\hline & Left TCSA.(Left MF+Left ES mm²) & $0.271^{*}$ & $0.422^{*}$ & -0.114 & -0.108 & 0.055 \\
\hline \multirow[t]{6}{*}{ Rad } & Right MF.(CSA,mm²) & $-0.281^{*}$ & 0.120 & -0.165 & -0.093 & -0.138 \\
\hline & Left MF.(CSA,mm²) & -0.125 & 0.220 & -0.007 & -0.089 & -0.051 \\
\hline & Right ES.(CSA,mm²) & -0.027 & 0.088 & -0.073 & 0.183 & 0.133 \\
\hline & Left ES.(CSA,mm²) & 0.016 & -0.004 & -0.074 & 0.270 & 0.208 \\
\hline & Right TCSA.(Right MF+Right ES mm²) & -0.110 & 0.116 & -0.116 & 0.135 & 0.076 \\
\hline & Left TCSA.(Left MF+Left ES mm²) & -0.032 & 0.079 & -0.070 & 0.211 & 0.169 \\
\hline
\end{tabular}

*Significant correlation at the level of 1\%, MF: Lumbar musculus multifidus, ES: Lumbar musculus erektor spinae, VAS: Visual Analog Scale, LBP: Low Back Pain

The fat infiltration values according to the groups are shown in Table 4. A significant difference was seen between the groups in the fat infiltration of the right MF ( $p=0.015)$. Grade 2 fat infiltration (10\%-50\%) was determined in $72 \%$ of the Non-rad group and in $56.9 \%$ of the Rad group. Grade 3 fat infiltration $(>50 \%)$ was seen at a higher rate in the right and left MF and left ES in the Rad group than in the Non-rad group.

Table 4 Comparisons of the fat infiltration values of the MF and ES of the groups 


\begin{tabular}{lllll}
\multicolumn{1}{l}{} & Non-rad & Rad & Total & P \\
\cline { 1 - 4 } Fat Infiltration_Right MF & & & & \\
\cline { 1 - 5 }$<10 \%$ & $36(21.4)$ & $47(30.7)$ & $83(25.9)$ & 0.015 \\
\cline { 1 - 5 } $10 \%-50 \%$ & $121(72)^{\mathrm{a}}$ & $87(56.9)^{\mathrm{b}}$ & $208(64.8)$ & \\
\cline { 1 - 5 }$>50 \%$ & $11(6.5)^{\mathrm{a}}$ & $19(12.4)^{\mathrm{b}}$ & $30(9.3)$ &
\end{tabular}

Fat Infiltration_Left MF

\begin{tabular}{lllll}
\hline$<10 \%$ & $43(25.6)$ & $42(27.5)$ & $85(26.5)$ & \multirow{2}{*}{0.088} \\
\cline { 1 - 3 } $10 \%-50 \%$ & $116(69)$ & $93(60.8)$ & $209(65.1)$ & \\
\cline { 1 - 3 }$>50 \%$ & $9(5.4)$ & $18(11.8)$ & $27(8.4)$ &
\end{tabular}

Fat Infiltration_Right ES

\begin{tabular}{|c|c|c|c|}
\hline$<10 \%$ & $40(23.8)$ & 31 (20.3) & 71 (22.1) \\
\hline $10 \%-50 \%$ & $111(66.1)$ & 108 (70.6) & 219 (68.2) \\
\hline$>50 \%$ & $17(10.1)$ & $14(9.2)$ & 31 (9.7) \\
\hline
\end{tabular}

Fat Infiltration_Left ES

\begin{tabular}{|c|c|c|c|}
\hline$<10 \%$ & $41(24.4)$ & 33 (21.6) & $74(23.1)$ \\
\hline $10 \%-50 \%$ & $118(70.2)$ & $105(68.6)$ & $223(69.5)$ \\
\hline$>50 \%$ & $9(5.4)$ & $15(9.8)$ & $24(7.5)$ \\
\hline
\end{tabular}

a-a. No difference between groups with the same letter, ${ }^{a-b}$ : A difference was determined between groups with different letters

A significant difference was determined in right and left MF fat infiltration according to age, $B M I$ and pain duration $(p<0.001, p<0.001, p=0.004, p<0.001$, $p<0.001, p=0.003$, respectively), and no difference was determined according to VAS activity and VAS resting scores $(p=0.129, p=0.062, p=0.423, p=0.300$, respectively).

A significant difference was determined in right and left ES fat infiltration according to age, $B M I$ and pain duration $(p<0.001, p<0.001, p<0.001$, respectively), and no difference was determined according to VAS activity and VAS resting scores ( $p=0.251, p=0.359$, respectively).

The comparisons of categorical data according to fat infiltrations are shown in Table 5. No difference was seen in the fat infiltrations according to herniation level and radiculopathy side. When examined according to segments, in the right and left MF and ES, the rate of Grade 1 (<10\%) fat infiltration was higher in the L3-L4 segment, and Grade 2 (10\%-50\%) fat infiltration was higher in L4-L5 and L5-S1 segments. When examined according to gender, a significantly higher rate of fat infiltration was seen in females than in males $(p<0.001)$.

Table 5 Comparisons of categorical data according to fat infiltrations 


\begin{tabular}{|c|c|c|c|c|c|c|c|c|c|c|c|}
\hline & \multicolumn{3}{|c|}{ Hernia level } & \multicolumn{3}{|c|}{ Radiculopathy side } & \multicolumn{3}{|l|}{ Segment } & \multicolumn{2}{|l|}{ Gender } \\
\hline & L3-L4 & L4-L5 & L5-S1 & Bilateral & Right & Left & L3-L4 & L4-L5 & L5-S1 & Male & Female \\
\hline \multicolumn{12}{|l|}{ Right MF } \\
\hline$<10 \%$ & $\begin{array}{l}23 \\
(41.1)\end{array}$ & $40(44)$ & $\begin{array}{l}39 \\
(51.3)\end{array}$ & $6(54.5)$ & $8(47.1)$ & $13(56.5)$ & $52(48.6)^{a}$ & $20(18.7)^{b}$ & $11(10.3)^{b}$ & $44(48.9)^{a}$ & $39(16.9)^{b}$ \\
\hline $10 \%-50 \%$ & $\begin{array}{l}29 \\
(51.8)\end{array}$ & $\begin{array}{l}47 \\
(51.6)\end{array}$ & $\begin{array}{l}33 \\
(43.4)\end{array}$ & $4(36.4)$ & $8(47.1)$ & $10(43.5)$ & $51(47.7)^{a}$ & $79(73.8)^{b}$ & $78(72.9)^{b}$ & $45(50)^{a}$ & $163(70.6)^{\mathrm{b}}$ \\
\hline$>50 \%$ & $4(7.1)$ & $4(4.4)$ & $4(5.3)$ & $1(9.1)$ & $1(5.9)$ & $0(0)$ & $4(3.7)^{a}$ & $8(7.5)^{a b}$ & $18(16.8)^{b}$ & $1(1.1)^{a}$ & $29(12.6)^{b}$ \\
\hline \multicolumn{12}{|l|}{ Left MF } \\
\hline$<10 \%$ & $\begin{array}{l}24 \\
(42.9)\end{array}$ & $\begin{array}{l}43 \\
(47.3)\end{array}$ & $\begin{array}{l}39 \\
(51.3)\end{array}$ & $4(36.4)$ & $8(47.1)$ & $13(56.5)$ & $55(51.4)^{a}$ & $21(19.6)^{b}$ & $9(8.4)^{b}$ & $44(48.9)^{a}$ & $41(17.7)^{b}$ \\
\hline $10 \%-50 \%$ & $\begin{array}{l}27 \\
(48.2)\end{array}$ & $\begin{array}{l}43 \\
(47.3)\end{array}$ & $\begin{array}{l}33 \\
(43.4)\end{array}$ & $6(54.5)$ & $7(41.2)$ & $10(43.5)$ & $47(43.9)^{a}$ & $79(73.8)^{b}$ & $83(77.6)^{b}$ & $45(50)^{a}$ & $164(71)^{b}$ \\
\hline$>50 \%$ & $5(8.9)$ & $5(5.5)$ & $4(5.3)$ & $1(9.1)$ & $2(11.8)$ & $0(0)$ & $5(4.7)$ & $7(6.5)$ & $15(14)$ & $1(1.1)^{a}$ & $26(11.3)^{b}$ \\
\hline \multicolumn{12}{|l|}{ Right ES } \\
\hline$<10 \%$ & $\begin{array}{l}17 \\
(30.4)\end{array}$ & $\begin{array}{l}34 \\
(37.4)\end{array}$ & $\begin{array}{l}32 \\
(42.1)\end{array}$ & $3(27.3)$ & $5(29.4)$ & $11(47.8)$ & $47(43.9)^{a}$ & $18(16.8)^{b}$ & $6(5.6)^{c}$ & $33(36.7)^{a}$ & $38(16.5)^{b}$ \\
\hline $10 \%-50 \%$ & $\begin{array}{l}38 \\
(67.9)\end{array}$ & $\begin{array}{l}56 \\
(61.5)\end{array}$ & $\begin{array}{l}43 \\
(56.6)\end{array}$ & $8(72.7)$ & $\begin{array}{l}12 \\
(70.6)\end{array}$ & $12(52.2)$ & $59(55.1)^{a}$ & $83(77.6)^{b}$ & $77(72)^{b}$ & $56(62.2)^{a}$ & $163(70.6)^{a}$ \\
\hline$>50 \%$ & $1(1.8)$ & $1(1.1)$ & $1(1.3)$ & & & & $1(0.9)^{a}$ & $6(5.6)^{a}$ & $24(22.4)^{b}$ & $1(1.1)^{a}$ & $30(13)^{b}$ \\
\hline \multicolumn{12}{|l|}{ Left ES } \\
\hline$<10 \%$ & $\begin{array}{l}19 \\
(33.9)\end{array}$ & $\begin{array}{l}37 \\
(40.7)\end{array}$ & $\begin{array}{l}33 \\
(43.4)\end{array}$ & $3(27.3)$ & $5(29.4)$ & $11(47.8)$ & $50(46.7)^{a}$ & $19(17.8)^{b}$ & $5(4.7)^{\mathrm{c}}$ & $38(42.2)^{a}$ & $36(15.6)^{b}$ \\
\hline $10 \%-50 \%$ & $\begin{array}{l}37 \\
(66.1)\end{array}$ & $\begin{array}{l}54 \\
(59.3)\end{array}$ & $\begin{array}{l}43 \\
(56.6)\end{array}$ & $8(72.7)$ & $\begin{array}{l}12 \\
(70.6)\end{array}$ & $12(52.2)$ & $57(53.3)^{a}$ & $84(78.5)^{b}$ & $82(76.6)^{b}$ & $49(54.4)^{a}$ & $174(75.3)^{\mathrm{b}}$ \\
\hline$>50 \%$ & $0(0)$ & $0(0)$ & $0(0)$ & & & & $0(0)^{a}$ & $4(3.7)^{a}$ & $20(18.7)^{b}$ & $3(3.3)^{a}$ & $21(9.1)^{b}$ \\
\hline
\end{tabular}

a-a, b-b: No difference between groups with the same letter, ${ }^{a-b-c}$ : A difference was determined between groups with different letters

The distribution of fat infiltration in the MF and ES according to the number of herniations is shown in Table 6. The right and left ES distributions showed a significant difference $(p<0.001)$. A difference was seen in distribution between patients with one herniation and those with three herniations. The rate of Grade $1(<10 \%)$ fat infiltration was higher in cases with a single herniation, and as the number of herniations increased, so the rate and severity of fat infiltration increased.

Table 6 Distribution of fat infiltration in the MF and ES according to the number of herniations 
Number of herniations

\begin{tabular}{|c|c|c|c|}
\hline & 1 & 2 & 3 \\
\hline \multicolumn{4}{|l|}{ Right MF } \\
\hline$<10 \%$ & $18(56.3)$ & 18 (52.9) & $16(39)$ \\
\hline $10 \%-50 \%$ & $14(43.8)$ & $16(47.1)$ & $21(51.2)$ \\
\hline$>50 \%$ & $0(0)$ & $0(0)$ & $4(9.8)$ \\
\hline \multicolumn{4}{|l|}{ Left MF } \\
\hline$<10 \%$ & $20(62.5)$ & $19(55.9)$ & $16(39)$ \\
\hline $10 \%-50 \%$ & $12(37.5)$ & $14(41.2)$ & $21(51.2)$ \\
\hline$>50 \%$ & $0(0)$ & $1(2.9)$ & $4(9.8)$ \\
\hline \multicolumn{4}{|l|}{ Right ES } \\
\hline$<10 \%$ & $21(65.6)^{a}$ & $16(47.1)^{\mathrm{ab}}$ & $10(24.4)^{b}$ \\
\hline $10 \%-50 \%$ & $11(34.4)^{a}$ & $18(52.9)^{\mathrm{ab}}$ & $30(73.2)^{b}$ \\
\hline$>50 \%$ & $0(0)$ & $0(0)$ & $1(2.4)$ \\
\hline \multicolumn{4}{|l|}{ Left ES } \\
\hline$<10 \%$ & $22(68.8)^{a}$ & $17(50)^{\mathrm{ab}}$ & $11(26.8)^{b}$ \\
\hline $10 \%-50 \%$ & $10(31.3)^{a}$ & $17(50)^{\mathrm{ab}}$ & $30(73.2)^{b}$ \\
\hline$>50 \%$ & - & - & - \\
\hline
\end{tabular}

a-a, b-b, ab-ab: No difference between groups with the same letter, ${ }^{a-b}$ : A difference was determined between groups with different letters, ${ }^{\text {ab: }}$ There was no difference from the other two groups

The comparisons of the presence of asymmetry according to the groups are shown in Table 7. No difference was determined between the groups in respect of MF and ES asymmetry. No difference was determined between the groups in respect of TCSA asymmetry.

Table 7 Comparisons of the presence of asymmetry according to the groups.

\begin{tabular}{lllll} 
& Non-rad & Rad & Total & $p$ \\
\hline MF & $60(35.7)$ & $58(37.9)$ & $118(36.8)$ & 0.684 \\
\hline ES & $64(38.1)$ & $59(38.6)$ & $123(38.3)$ & 0.932 \\
\hline TCSA & $36(21.4)$ & $35(22.9)$ & $71(22.1)$ & 0.755
\end{tabular}

MF: Lumbar musculus multifidus, ES: Lumbar musculus erector spinae, TCSA: Total cross-sectional area, Non-rad: Lumbar disc herniation group without radiculopathy, Rad: Lumbar disc herniation group with radiculopathy

When the general levels of herniation were examined, in the Non-rad group, bilateral herniation was determined in $85.7 \%$, on the right side in $3.6 \%$, and on the left side in $10.7 \%$. In the Rad group, these rates were bilateral in $63.5 \%$, right-side in $38.5 \%$, and left-side in $61.5 \%$.

The levels of herniation according to segments were: in the Non-rad group, 46.4\% in L3-L4 segment, 88.1\% in L4-L5 segment, and 62.5\% in L5-S1 segment, and in the Rad group, 58.8\% in L3-L4 segment, 88.2\% in L4-L5 segment, and 80.4\% in L5-S1 segment.

\section{Discussion}

In the results of this study, no significant difference was seen in the CSA values between the groups. Only the mean CSA value in the right ES was lower in the Non-rad group and similarly the mean right TCSA values were lower. In a study by Hyun et al [49] of groups with disc herniation with and without radiculopathy, no significant difference was observed between the sides in respect of the TCSA or functional CSA (FCSA), but the FCSA values were seen to be higher in the group without radiculopathy than in the group with radiculopathy. In another study of patients operated on because of LDH, no difference was seen in the paraspinal muscle CSA values compared with the less affected side [50]. Some studies have reported hypertrophy of the MF CSA compared to control subjects [25,51]. In the current study, that the right ES CSA and right TCSA values of the Non-rad group were lower than those of the Rad group suggests that increased CSA (pseudohypertrophy) had developed associated with severe fat infiltration of $>50 \%$ in the Rad group. Despite a decrease in FCSA when there is peudohypertrophy, an increase is observed in TCSA because of the increasing fat tissue [18, 19]. The findings determined in the current study support this view. 
Grade 3 fat infiltration (>50\%) was determined in the current study at a higher rate in the Rad group than in the Non-rad group. Ji Hye Min et al [21] reported a relationship between radiculopathy and fat infiltration in the MF muscle associated with more severe and widespread atrophy. Kader et al [52] determined MF atrophy associated with fat infiltration in $80 \%$ of cases with disc degeneration and nerve compression determined on MRI, and showed that there was more severe and widespread MF atrophy in patients with radiculopathy compared to those without. Chen et al [16] showed that in patients with radiculopathy applied with microdiscectomy, markers for impaired muscle regeneration were associated with worse outcomes. In an experimental study of disc injury, Hodge et al $[53,54]$ reported that after 6 months there was an increase histologically in fat and connective tissue in the MF, but atrophy was not determined, and these findings were stated to be compatible with gene expression data from cytokines that play a role in both adipogenesis and fibrosis. It has been suggested that fat infiltration in muscles mediated by pro-inflammatory cytokines and muscle inhibition in the acute and subacute phase is associated with non-use in later stages [17]. Similar to these findings in literature, grade 2 and 3 fat infiltration and associated muscle atrophy was determined in $73.3 \%-77.9 \%$ of the subjects in both groups of the current study [42, 52]. As in other studies, atrophy associated with fat infiltration was evident especially at the L5-S1 level $[19,21,52]$. As the number of herniations increased, so the ratio of involvement in the right-left ES muscles and severity of fat infiltration statistically significantly increased. Although the levels of fat infiltration seem to be similar between the Rad and Non-rad groups, a higher rate of severe $(>50 \%)$ fat infiltration was observed in the Rad group. This suggests that the nerve root compression originates from the increased severity of degeneration in the paraspinal muscles. When intervertebral foramens are under pressure (disc-related nerve root compression, spinal stenosis), denervation may explain fat infiltration and atrophy [55]. The results of the current study were consistent with findings in literature.

No difference was found between the two groups in respect of asymmetry in the current study. Previous studies of healthy individuals have reported differences of $3 \pm 4 \%$ [56], and $7.2 \pm 9.6 \%$ [57] between the right and left sides compared to the largest edge. Based on these results, it has been reported that a difference of $>10 \%$ can be defined as asymmetry [19]. Kader et al [52] stated that the majority of muscle degeneration in patients with unilateral radiculopathy at a single level was bilateral and multi-level. Ji Hye Min et al [21] found no difference in MF asymmetry between bilateral and unilateral nerve root compression and bilateral MF atrophy in most patients with unilateral radiculopathy. In a study by Fortin et al [26], there was stated to be no significant MF asymmetry at the upper or lower spinal level of the level of disc herniation. As a result of the current study, it was seen that muscle degeneration was not only on the side of disc herniation and nerve compression, but it also developed on the contralateral side and/or in the upper and lower segments. In addition, it was thought that there was no difference between the groups in respect of asymmetry because the muscle atrophy and fat infiltration were distributed equally on the right and left sides. Thus it can be concluded that in LDH cases with and without nerve compression, muscle degeneration developed after 3 months regardless of the herniation side, and as stated in acute unilateral cases [20], degeneration is not localised only on the side of the herniated disc but is widespread, involving the opposite segment and/or upper and lower segments. The current study results were consistent with the literature. However, in some studies there has been stated to be a relationship between paraspinal muscle asymmetry and unilateral low back pain with or without radiculopathy $[22,24,27,28,56]$.

In the current study, the CSA and TCSA values of males were found to be higher than those of females. Previous studies have also shown greater CSA and higher density of paraspinal muscles in males than in females $[11,19,21,52,58,59]$. The current study results were consistent with literature.

The results of the current study demonstrated a weak and moderate level relationship between the CSA and TCSA values of the muscles and age and BMI. Studies in literature have reported different results related to age. Some studies have stated that the CSA of muscles decreases with age [19, 21, 52, 59, 60] while others have shown no such relationship [48, 58,61,62]. Some studies have determined a significant correlation between BMI and muscle values and have stated that paraspinal muscle changes are related to BMI [63], whereas others have stated that there is no relationship between BMI and CSA [42, 48, $60]$.

In the current study, age, gender, BMI, and duration of pain were found to be related to fat infiltration. A higher rate of fat infiltration was determined in females than in males. An increase in fat infiltration with ageing was seen in both groups, and as BMI increased, there was seen to be an increase in fat infiltration. As the duration of pain increased, the rate of fat infiltration was seen to increasee in both groups. Fat infiltration of the praspinal muscles was generally observed in the area adjacent to the vertebra. In literature, there has been stated to be a higher rate of fat infiltration in females than in males [42, $64,65]$. Kjaer et al [42] suggested that the significant difference in fat in the MF muscles of males and females could be a result of differences in body composition, and the higher rate of body fat in females could be reflected as a higher rate of fat infiltration in the MF in females. Studies in literature have stated that fat infiltration increases together with ageing $[64,66,67,68]$. Mcloughlin et al [67] determined a relationship between paraspinal fat accumulation and age and the amount of subcutaneous fat, and stated that this was a sign of paraspinal muscle atrophy in patients who have not undergone surgery. Some studies have shown a relationship between BMI and fat infiltration [14, 61], while others have found no relationship [42, 60]. In three studies by Ranger et al which examined the relationship between MF fat infiltration and the duration of pain, there was said to be limited evidence of no significant relationship between periods of lesss than or more than one year and fat infiltration [23]. According to the results of another study, there was found to be a relationship between the duration of pain and the severity of MF muscle atrophy, although not of a statisitically significant level, and it was stated that high pain scores tended to show a potential increase in muscle atrophy [19].

In the current study, fat infiltration was determined to be lowest at L3-L4 and greatest at L5-S1. According to the group-segment interaction, the right ES CSA was lowest in the L5-S1 segment in the Rad group which was lower than in the Non-rad group. Involvement in the MF was more at L4-L5 and L5-S1, and in the ES, more at L5-S1.

Muscles are tissues with the capacity to renew. Under various stimuli (neural activation, denervation, wounds and an inflammatory environment, exercise, flexion, and overloading), changes may occur in muscle measurements, and this affects the muscle strength capability [69]. In individuals undertaking regular physical activity, the proinflammatory response against intervertebral disc degeneration is reduced, fibrosis is reduced, and through regulation of the gene network in the MF, most harmful effects are prevented [30]. To reverse, reduce, or halt the degenerative changes in the paraspinal muscles, which 
are seen related to LDH, it is important that pharmacological treatment and appropriate exercise programs determined according to the psychological and social status of the patient are applied, and that patients presenting at the clinic are informed about and referred to these exercise programs.

A limitation of the current study was that there was no control group. Therefore no comparison could be made with the fat infiltration level and asymmetry of healthy subjects. However, previous studies of healthy subjects have reported a relationship between fat infiltration and LDH, and that there is asymmetry of $>10 \%$ difference between the right and left sides $[13,19,21,26]$.

\section{Conclusion}

In conclusion, there seems to be a relationship between widespread ( 2 or more lumbar segments) involvement of the lumbar paraspinal muscles together with severe $(>50 \%)$ fat infiltration and radiculopathy. This seems to be associated with increased severity of muscle degeneration related to denervation when invertebral foramen are under pressure (disc-related nerve root compression. This result may predict the necessity of correcting or removing root compression with appropriate methods in patients with radiculopathy.

\section{Abbreviations}

MF

Lumbar Musculus Multifidus

ES

Lumbar Musculus Erector Spinae

MRI

Magnetic Resonance Imaging

CSA

Cross-sectional area

TCSA

Total cross-sectional area

FCSA

Functional cross-sectional area

VAS

Visual Analog Scale

$\mathrm{LDH}$

Lumbar Disc Herniation BMl:Body mass index

EMG

Electromyography

CT

Computed Tomography

Non-rad

Lumbar disc herniation group without radiculopathy

Rad

Lumbar disc herniation group with radiculopathy

\section{Declarations}

\section{Ethical Approval and Consent}

The study was conducted in compliance with the principles of the Helsinki Declaration. Approval for the study was granted by the Ethics Committee of Near East University (YDU/2021/87-1273). All the participants provided informed consent.

\section{Consent for publication}

The patients consented to the publication of their pictures as well as their anonymous and clustered data.

\section{Data and materials availability}

The data obtained and analyzed in this study is not available to the public because of ethical regulations and local management procedures, but can be obtained on request from corresponding author.

\section{Competing interests}

The authors declare that they have no competing interests.

\section{Funding}


No funding for this study was provided from any source.

\section{Author Contributions}

A.Y. and T.Y. designed the study, interpreted the data, and made major contributions to the writing of the article. A.Y. evaluated the suitability of the patients and referred potential participants to the polyclinics. All the authors examined the final draft of the manuscript, made changes, and approved

\section{Acknowledgements}

The authors would like to thank Radiology Specialist, Doctor Kerim Temiz for contributing to the MRI interpretations, technician, Halil Ibrahim Efe, for performing the MRI scans and the Application Specialist, Ibrahim Yeşilyurt, for assisting with adaptation of the MRI device to the study.

\section{References}

1. Jordan J, Konstantinou K, O'Dowd J. Herniated lumbar disc. BMJ Clin Evid. 2009;1118.

2. Fjeld OR, Grøvle L, Helgeland J, Småstuen MC, Solberg TK, Zwart JA, et al. Complications, reoperations, readmissions, and length of hospital stay in 34 639 surgical cases of lumbar disc herniation. Bone Joint J. 2019;101-B(4):470-477.

3. Schwarzer AC, Aprill CN, Derby R, Fortin J, Kine G, Bogduk N. The prevalence and clinical features of internal disc disruption in patients with chronic low back pain. Spine (Phila Pa 1976). 1995;20(17):1878-83.

4. Rubin DI. Epidemiology and risk factors for spine pain. Neurol Clin 2007;25:353-371.

5. Brinjikji W, Luetmer PH, Comstock B, Bresnahan BW, Chen LE, Deyo RA, et al. Systematic literature review of imaging features of spinal degeneration in asymptomatic populations. AJNR Am J Neuroradiol. 2015;36(4):811-6.

6. Hoy D, March L, Brooks P, Blyth F, Woolf A, Bain C, et al. The global burden of low back pain: estimates from the Global Burden of Disease 2010 study. Ann Rheum Dis. 2014;73(6):968-74.

7. Kong WZ, Goel VK, Gilbertson LG, Weinstein JN. Effects of muscle dysfunction on lumbar spine mechanics. A finite element study based on a two motion segments model. Spine (Phila Pa 1976). 1996;21(19):2197-206;

8. Battié MC, Niemelainen R, Gibbons LE, Dhillon S. Is level- and side-specific multifidus asymmetry a marker for lumbar disc pathology? Spine J. 2012;12(10):932-9.

9. Fortin M, Gibbons LE, Videman T, Battié MC. Do variations in paraspinal muscle morphology and composition predict low back pain in men? Scand J MedSci Sports. 2015: 25(6): 880-887.

10. Rosatelli AL, Ravichandiran K, Agur AM. Three-dimensional study of the musculotendinous architecture of lumbar multifidus and its functional implications. Clin Anat. 2008;21(6):539-546.

11. Noonan AM, Brown SHM. Paraspinal muscle pathophysiology associated with low back pain and spine degenerative disorders. JOR Spine. 2021;4(3):e1171.

12. Agha O, Mueller-Immergluck A, Liu M, Zhang H, Theologis AA, Clark A, et al. Intervertebral disc herniation effects on multifidus muscle composition and resident stem cell populations. JOR Spine. 2020 May 6;3(2):e1091.

13. Danneels LA, Vanderstraeten GG, Cambier DC, Witvrouw EE, De Cuyper HJ. CT imaging of trunk muscles in chronic low back pain patients and healthy control subjects. Eur Spine J 2000: 9(4): 266-272.

14. Lee SH, Park SW, Kim YB, Nam TK, Lee YS. The fatty degeneration of lumbar paraspinal muscles on computed tomography scan according to age and disc level. Spine J. 2017;17:81-87.

15. Shahidi B, Fisch KM, Gibbons MC, Ward SR. Increased fibrogenic gene expression in multifidus muscles of patients with chronic versus acute lumbar spine pathology. Spine. 2020;45(4):E189-E195.

16. Chen X, Hodges PW, James G, Diwan AD. Do markers of inflammation and/or muscle regeneration in lumbar multifidus muscle and fat differ between individuals with good or poor outcome following microdiscectomy for lumbar disc herniation? Spine. 2021;46:678-686.

17. Hodges PW, Danneels L. Changes in structure and function of the back muscles in low back pain: different time points, observations, and mechanisms. J Orthop Sports Phys Ther. 2019;49(6):464-476.

18. Parkkola R, Rytokoski U, Kormano M. Magnetic resonance imaging of the discs and trunk muscles in patients with chronic low back pain and healthy control subjects. Spine. 1993;18:830-836.

19. Kalichman L, Carmeli E, Been E. The association between imaging parameters of the paraspinal muscles, spinal degeneration, and low back pain. Biomed Res Int. 2017;2562957.

20. Hodges P, Holm AK, Hansson T, Holm S. Rapid atrophy of the lumbar multifidus follows experimental disc or nerve root injury. Spine. 2006;31(25):2926-2933.

21. Min JH, Choi HS, Rhee WI, Lee. JI Association between radiculopathy and lumbar multifidus atrophy in magnetic resonance imaging. J Back Musculoskelet Rehabil. 26 (2013) 175-181.

22. Kim WH, Lee SH, Lee DY. Changes in the cross-sectional area of multifidus and psoas in unilateral sciatica caused by lumbar disc herniation. J Korean Neurosurg Soc. 2011;50(3):201. 
23. Ranger TA, Cicuttini FM, Jensen TS, Peiris WL, Hussain SM, Fairley J, et al. Is the size and composition of the paraspinal muscles associated with low back pain? A systematic review. Spine J 2017;17:1729-48.

24. Cooley JR, Walker BF, Ardakani EM, Kjaer P, Jensen TS, Hebert JJ. Relationships between paraspinal muscle morphology and neurocompressive conditions of the lumbar spine: a systematic review with meta-analysis. BMC Musculoskelet Disord. 2018;19(1):1-21.

25. Shahidi B, Hubbard JC, Gibbons MC, Ruoss S, Zlomislic V, Allen RT, et al. Lumbar multifidus muscle degenerates in individuals with chronic degenerative lumbar spine pathology. J Orthop Res. 2017;35(12):2700-2706.

26. Fortin M, Lazary A, Varga PP, McCall I, Battie MC. Paraspinal muscle asymmetry and fat infiltration in patients with symptomatic disc herniation. Eur Spine J. 2016; 25(5): 1452-1459.

27. Barker KL, Shamley DR, Jackson D. Changes in the cross-sectional area of multifidus and psoas in patients with unilateral back pain: the relationship to pain and disability. Spine. 2004;29:E515-E519.

28. Ploumis A, Michailidis N, Christodoulou P, Kalaitzoglou I, Gouvas G, Beris A. Ipsilateral atrophy of paraspinal and psoas muscle in unilateral back pain patients with monosegmental degenerative disc disease. Br J Radiol 2011: 84(1004): 709-713.

29. Agten A, Stevens S, Verbrugghe J, Timmermans A, Vandenabeele F. Biopsy samples from the erector spinae of persons with nonspecific chronic low back pain display a decrease in glycolytic muscle fibers. Spine J. 2020;20(2):199-206.

30. James G, Klyne DM, Millecamps M, Stone LS, Hodges PW. ISSLS prize in basic science 2019: physical activity attenuates fibrotic alterations to the multifidus muscle associated with intervertebral disc degeneration. Eur Spine J. 2019;28(5):893-904.

31. Cho TG, Park SW, Kim YB. Chronic paraspinal muscle injury model in rat. J Korean Neurosurg Soc. 2016;59(5):430.

32. Hu ZJ, Zhang JF, Xu WB, Zhao FD, Wang JY, Fan SW, et al. Effect of pure muscle retraction on multifidus injury and atrophy after posterior lumbar spine surgery with 24 weeks observation in a rabbit model. Eur Spine J. 2017;26(1):210-220.

33. James G, Sluka KA, Blomster L, Hall L, Schmid AB, Shu CC, et al. Macrophage polarization contributes to local inflammation and structural change in the multifidus muscle after intervertebral disc injury. Eur Spine J. 2018;27(8):1744-1756.

34. Maas $\mathrm{H}$, Noort W, Hodges PW, van Dieën J. Effects of intervertebral disc lesion and multifidus muscle resection on the structure of the lumbar intervertebral discs and paraspinal musculature of the rat. J Biomech. 2018;70:228-234.

35. Lerer A, Nykamp SG, Harriss AB, Gibson TW, Koch TG, Brown SH. MRI-based relationships between spine pathology, intervertebral disc degeneration, and muscle fatty infiltration in chondrodystrophic and non-chondrodystrophic dogs. Spine J. 2015;15(11):2433-2439.

36. Bergknut N, Rutges JP, Kranenburg HJ, Smolders LA, Hagman R, Smidt HJ, et al. The dog as an animal model for intervertebral disc degeneration? Spine (Phila Pa 1976). 2012;37(5):351-8.

37. Zhu XZ, Parnianpour M, Nordin M, Kahanovitz N. Histochemistryand morphology of erector spinae muscle in lumbar disc herniation.Spine. 1989;14(4):391-397.

38. Fardon DF. Nomenclature and classification of lumbar disc pathology. Spine. 2001;26:461-462.

39. Mysliwiec LW, Cholewicki J, Winkelpleck MD, Eis GP. MSU classification for herniated lumbar discs on MRI: toward developing objective criteria for surgical selection. Eur Spine J. 2010 Jul;19(7):1087-93.

40. Pfirrmann CW, Dora C, Schmid MR, Zanetti M, Hodler J, Boos N. MR image-based grading of lumbar nerve root compromise due to disk herniation: reliability study with surgical correlation. Radiology. 2004;230(2):583-8.

41. Kaliya-Perumal AK, Ariputhiran-Tamilselvam SK, Luo CA, Thiagarajan S, Selvam U, Sumathi-Edirolimanian RP. Revalidating Pfirrmann's Magnetic Resonance Image-Based Grading of Lumbar Nerve Root Compromise by Calculating Reliability among Orthopaedic Residents. Clin Orthop Surg. 2018;10(2):210-215.

42. Kjaer P, Bendix T, Sorensen JS, Korsholm L, Leboeuf-Yde C. Are MRI-defined fat infiltrations in the multifidus muscles associated with low back pain? BMC Med 2007: 5: 2.

43. Solgaard Sorensen J, Kjaer P, Jensen ST, Andersen P. Low- field magnetic resonance imaging of the lumbar spine: relia- bility of qualitative evaluation of disc and muscle parameters. Acta Radiol 2006; 47: 947-53.

44. Dulor JP, Cambon B, Vigneron P, Reyne Y, Nougues J, Casteilla L, et al. Expression of specific white adipose tissue genes in denervation-induced skeletal muscle fatty degeneration. FEBS Lett. 1998;439:89-92.

45. Crawford RJ, Cornwall J, Abbott R, Elliott JM. Manually defining regions of interest when quantifying paravertebral muscles fatty infiltration from axial magnetic resonance imaging: a proposed method for the lumbar spine with anatomical cross-reference. BMC Musculoskelet Disord. 2017;19:18(1):25.

46. Upadhyay B, Toms A. CT and MRI evaluation of paraspinal muscle degeneration. Europen Cociety of Radiology.

47. Hides JA, Richardson CA, Jull GA. Multifidus muscle recovery is not automatic after resolution of acute, first-episode low back pain. Spine. 1996;21(23):2763-9.

48. Kamaz M, Kiresi D, Oguz H, Emlik D, Levendoglu F. CT measurement of trunk muscle areas in patients with chronic low back pain. Diagn Interv Radiol 2007: 13 (3): 144-148.

49. Hyun JK, Lee JY, Lee SJ, Jeon JY. Asymmetric atrophy of mul- tifidus muscle in patients with unilateral lumbosacral radicu- lopathy. Spine 2007; 32 : E598-602.

50. Ford D, Bagnall KM, McFadden KD, Greenhill B, Raso J. Analysis of vertebral muscle obtained during surgery for correction of a lumbar disc disorder. Cells Tissues Organs. 1983;116(2):152-157.

Page $12 / 14$ 
51. Bajek S, Bobinac D, Bajek G, Vranic TS, Lah B, Dragojevic DM. Muscle fiber type distribution in multifidus muscle in cases of lumbar disc herniation. Acta Medica Okayama. 2000;54(6):235-242.

52. Kader DF, Wardlaw D, Smith FW. Correlation between the MRI changes in the lumbar multifidus muscles and leg pain. Clin Radiol. $2000 ; 55$ : 145-9.

53. Hodges PW, James G, Blomster L, Hall L, Schmid AB, Shu C, et al. Can proinflammatory cytokine gene expression explain multifidus muscle fiber changes after an intervertebral disc lesion? Spine (Phila Pa 1976). 2014;39(13):1010-7.

54. Hodges PW, James G, Blomster L, Hall L, Schmid A, Shu C, et al. Multifidus Muscle Changes After Back Injury Are Characterized by Structural Remodeling of Muscle, Adipose and Connective Tissue, but Not Muscle Atrophy: Molecular and Morphological Evidence. Spine (Phila Pa 1976). 2015;40(14):1057-71.

55. Yoshihara K, Nakayama Y, Fujii N, Aoki T, Ito H. Atrophy of the multifidus muscle in patients with lumbar disk herniation: histochemical and electromyographic study. Orthopedics. 2003;26:493-495.

56. Hides J, Stokes MJ, Saide M, Jull GA, Cooper DH. Evidence of lumbar multifidus muscles wasting ipsilateral to symptoms in patients with acute/subacute low back pain. Spine 1994; 19:165-172.

57. Stokes M, Rankin G, Newham DJ. Ultrasound imaging of lumbar multifidus muscle: normal reference ranges for mea- surements and practical guidance on the technique. Man Ther. 2005;10(2):116-126.

58. Hides J, Gilmore C, Stanton W, Bohlscheid E. Multifidus size and symmetry among chronic LBP and healthy asymptomatic subjects. Man Ther 2008a: 13 (1): 43-49.

59. Kalichman L, Hodges P, Li L, Guermazi A, Hunter DJ. Changes in paraspinal muscles and their association with low back pain and spinal degeneration: CT study. Eur Spine J. 2010; 19(7): 1136-1144.

60. Parkkola R, Kormano M. Lumbar disc and back muscle degeneration on MRI: Correlation to age and body mass. J Spinal Disord. 1992; 5(1): 86-92.

61. Takayama K, Kita T, Nakamura H, Kanematsu F, Yasunami T, Sakanaka H, et al. New predictive index for lumbar paraspinal muscle degeneration associated with aging. Spine, 2016; 41(2): E84-E90.

62. Cuellar WA, Wilson A, Blizzard CL, Otahal P, Callisaya ML, Hides JA, et al. The assessment of abdominal and multifidus muscles and their role in physical function in older adults: a systematic review, Physiotherapy. 2017; 103(1): 21-39.

63. Fortin M, Videman T, Gibbons LE, Battie MC. Paraspinal muscle morphology and composition: a 15-yr longitudinal magnetic resonance imaging study. Med Sci Sports Exerc. 2014; 46(5): 893-901.

64. Ogon I, Takebayashi T, Takashima H, Morita T, Yoshimoto M, Terashima Y, et al. Quantitative Analysis Concerning Atrophy and Fat Infiltration of the Multifidus Muscle with Magnetic Resonance Spectroscopy in Chronic Low Back Pain. Spine Surg Relat Res. 2018 Oct 10;3(2):163-170.

65. Crawford RJ, Volken T, Ni Mhuiris Á, Bow CC, Elliott JM, Hoggarth MA, et al. Geography of Lumbar Paravertebral Muscle Fatty Infiltration: The Influence of Demographics, Low Back Pain, and Disability. Spine (Phila Pa 1976). 2019;44(18):1294-1302.

66. Shahidi B, Gibbons MC, Esparza M, Zlomislic V, Allen RT, Garfin SR, et al. Cell populations and muscle fiber morphology associated with acute and chronic muscle degeneration in lumbar spine pathology. JOR Spine. 2020;3(2):e1087.

67. McLoughlin RF, D’Arcy EM, Brittain MM, Fitzgerald O, Masterson JB. The significance of fat and muscle areas in the lumbar paraspinal space: a CT study. J Comput Assisted Tomogr 1994:18(2): 275-278.

68. Crawford RJ, Filli L, Elliott JM, Nanz D, Fischer MA, Marcon M, et al. Age- and Level-Dependence of Fatty Infiltration in Lumbar Paravertebral Muscles of Healthy Volunteers. AJNR Am J Neuroradiol. 2016;37(4):742-8.

69. Lieber RL. Skeletal Muscle Structure, Function, and Plasticity. Baltimore, MD: Lippincott Williams \& Wilkins; 2008.

\section{Figures}
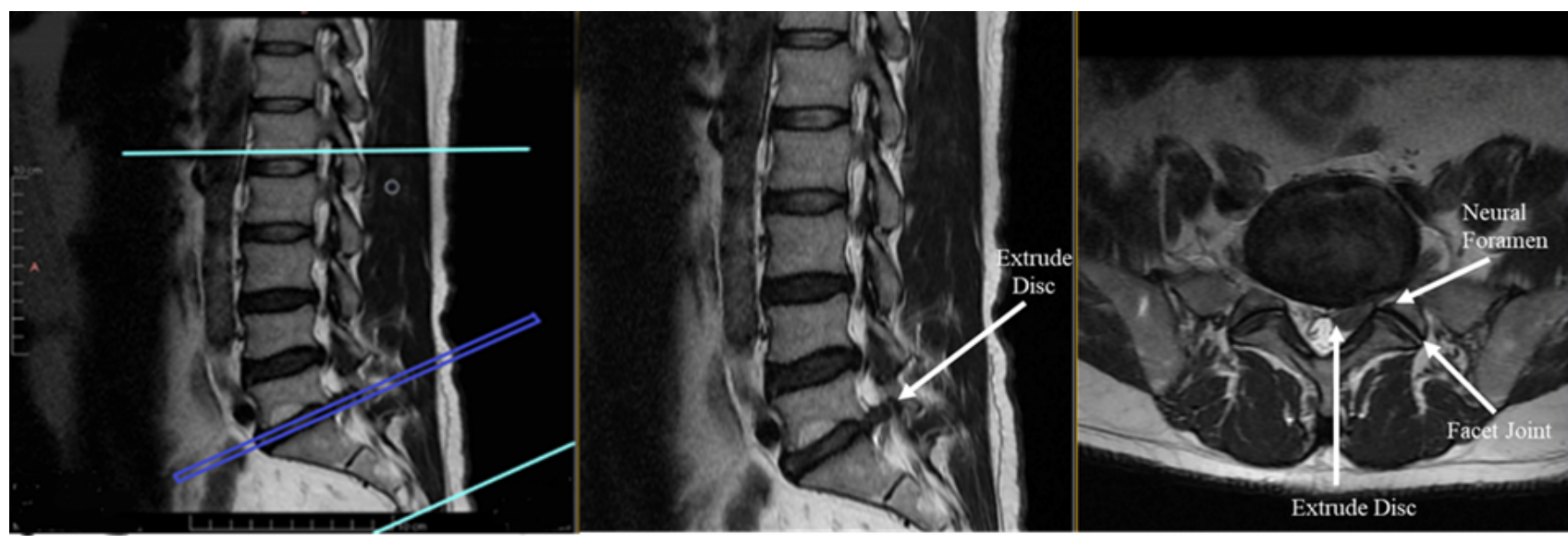

Figure 1 
T2 sagittal and axial slices of L5-S1 of a patient in the radiculopathy group, showing more evident narrowing of both neural foramen on the left side, indentation in the anterior epidural fat distance, obliterating the left lateral recess, contact with the S1 nerve root, and the appearance of extruding disc.

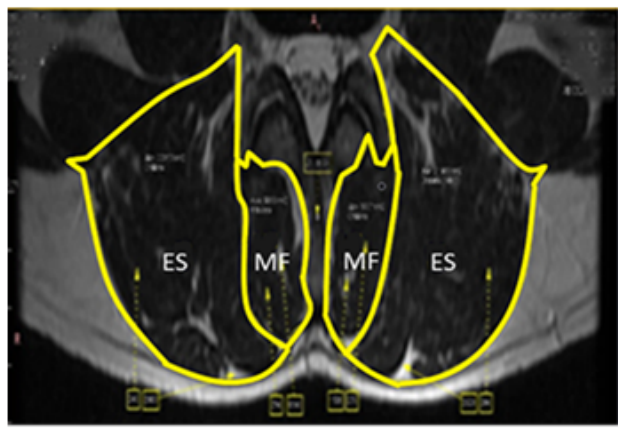

(A)

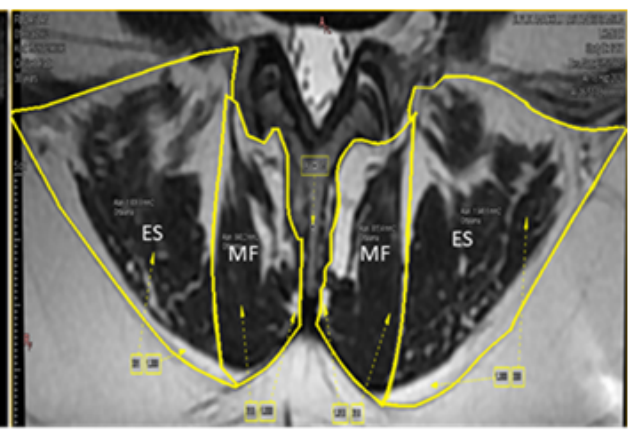

(B)

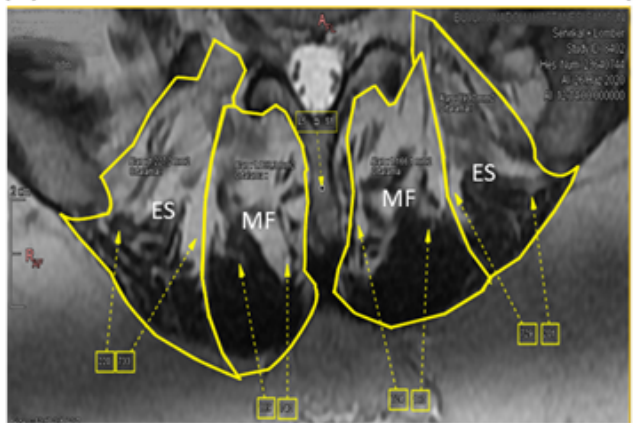

(C)

\section{Figure 2}

Degrees of fat infiltration MF: Musculus multifidus, ES: Musculus erektor spinae and

(A) Grade 1: $<\% 10$ fat infiltration

(B) Grade 2: $10 \%-50 \%$ fat infiltration

(C) Grade 3: $>50 \%$ fat infiltration 